\title{
Effects of Aromatase Inhibition on the Physical Activity Levels of Male Mice
}

\author{
Robert S Bowen ${ }^{1,2 *}$, David P Ferguson ${ }^{2,3}$ and J Timothy Lightfoot ${ }^{2,3}$
}

${ }^{1}$ Science and Mathematics Division, Truett-McConnell College, Cleveland, GA 30528, USA

${ }^{2}$ Department of Kinesiology, University of North Carolina Charlotte, Charlotte, NC 28223, USA

${ }^{3}$ Department of Health and Kinesiology, Texas A\&M University, College Station, TX 77845, USA

\begin{abstract}
Increasing activity levels in an inactive population can lead to associative increases in health and well-being. Both biologic and genetic factors have been identified that alter physical activity levels in humans and rodents with an extensive early literature regarding sex steroid effects on physical activity. Currently, it is suggested that the androgens require conversion to estrogens prior to eliciting any effects on activity patterns. Recent data contradicts this assertion; thus, the purpose of this study was to evaluate the necessity of the aromatase complex in activity regulation. Wheel running was assessed in male C57BL/6J mice under various sex steroid-disrupted and aromatase-inhibited conditions. Inhibition of the aromatase complex was achieved through administration of two different aromatase inhibiting substances-letrozole and exemestane. Wheel running was unaffected by aromatase inhibition in reproductively intact and sex steroid supplemented mice. Orchidectomy significantly reduced wheel running activity. Steroid replacement recovered wheel running to pre-surgical levels; however, aromatase inhibition did not further affect wheel running levels. The recovery of wheel running in mice with androgen supplementation and the further persistence of wheel running in mice with compromised aromatase function suggests that the androgens-testosterone in particular-may directly affect wheel running patterns in male mice.
\end{abstract}

Keywords: Sex Steroid; Sex Hormone; Locomotion; Exemestane; Letrozole

\section{Introduction}

Physical inactivity affects public health and unnecessarily burdens the health care system. The risks of many diseases including obesity, diabetes, heart disease and several types of cancer are enhanced in individuals with habitually low physical activity levels [1]. Although evidence exists suggesting that activity levels are determined by extrinsic and environmental factors, a growing number of scientific studies suggest large genetic and biological influences also exist [2-8]. Androgens and estrogens have been the focus of extensive research relating to activity levels in rodents. Notably, the surgical removal of testes or ovaries results in noted reductions in daily wheel running activity [9-13].

Currently, it is suggested that testosterone requires conversion to an estrogenic compound before any modulatory interactions to the wheel running response will occur. Roy and Wade [14] administered aromatizable and non-aromatizable forms of androgens to orchidectomized rats. The aromatizable androgen notably increased wheel running, but administration of the non-aromatizable molecule resulted in continued quiescence.

Supporting Roy and Wade's earlier study, Watai et al. [15] found that wheel running activity was hindered in an estrogen-deficient aromatase knockout mouse model. Conversely, Hill et al. [16], using a similar aromatase knockout model found that the male knockout animals ran nearly twice as far as wild type animals, an observation that was reversed in three weeks with the administration of $17 \beta$-estradiol. While the use of knockout animals can lead to difficulties with interpretation due to issues arising during development [17], it is interesting that the two studies using aromatase knockout animals resulted in completely opposite results.

Thus, other experimental methods, such as the use of aromataseinhibiting substances to circumvent the issues related to the use of knockout animals, are warranted for further elucidation of the roles of the sex steroids in physical activity regulation. With a pharmacological approach, the functionality of particular physiological pathways can be altered without hindering normal development. Therefore, the purpose of this study was to evaluate wheel running activity in the presence of irreversible and reversible aromatase inhibitors under normal physiological conditions and during artificial manipulation of endogenous sex steroid levels in male mice.

\section{Materials and Methods}

Eighty male C57BL/6J mice (Jackson Laboratories, Bar Harbor, $\mathrm{ME})$ were used in three experimental procedures. All mice were housed in an environmentally controlled animal husbandry facility under a $12 / 12 \mathrm{~h}$ light/dark cycle with lights illuminating the housing room at 6:00am daily. After arrival at the research facility, mice were initially housed with six to eight littermates prior to initiating experimental protocols. After acclimation and at approximately eight weeks of age $(\approx 54$ days old), the animals were individually housed in standard rat sized cages with metal running wheels during each experiment. The cages were equipped with a stainless metal food hopper and glass water bottle allowing ad libitum access to both food and water. Activity data collection began when the mice were 63 days of age. Physical activity levels are near a maximum and demonstrate low levels of variation

*Corresponding author: Robert S Bowen, 100 Alumni Drive, Science and Mathematics Division, Truett-McConnell College, Cleveland, GA 30528, USA, Tel: (706) 865-2136; E-mail: rbowen@truett.edu

Received August 12, 2011; Accepted November 25, 2011; Published November 25, 2011

Citation: Bowen RS, Ferguson DP, Lightfoot JT (2011) Effects of Aromatase Inhibition on the Physical Activity Levels of Male Mice. J Steroids Hormon Sci S1:001. doi:10.4172/2157-7536.S1-001

Copyright: (c) 2011 Bowen RS, et al. This is an open-access article distributed under the terms of the Creative Commons Attribution License, which permits unrestricted use, distribution, and reproduction in any medium, provided the original author and source are credited. 
across the ages utilized in this experiment [18] minimizing the effects of age on wheel running indices. This project conformed to the ethical standards set forth by the scientific community and was approved by the UNC Charlotte Institutional Animal Care and Use Committee prior to initiation.

Running wheels (450 mm circumference; Ware Manufacturing, Phoenix, AZ) with a $40 \mathrm{~mm}$ wide solid running surface were attached to the metal tops of each cage and were equipped with cycling computers (BC500, Sigma Sport, Olney, IL) to track wheel running distance $(\mathrm{km})$ and duration $(\mathrm{min})$. Average speeds $\left(\mathrm{m} \cdot \mathrm{min}^{-1}\right)$ for each day of analysis was calculated by dividing distance by duration. Each experimental epoch lasted seven days and wheel running data was collected every 24 hours. Average daily distance, duration, and speed were calculated for each seven day experimental epoch. Each computer was calibrated to the running wheel's circumference and was checked for proper connectivity on a daily basis by a research technician. Furthermore, the freeness of the wheel's rotation about the axle was checked daily and lubricated as needed. The wheels were sanitized every two weeks for the length of the experiments and were brushed when needed to keep the running surface free of debris (bedding, food, feces, etc.). The physical activity indices measured in this project have previously been shown to exhibit a high level of repeatability in our hands [19].

During this study, control and experimental injections of aromatase inhibitors were administered. Control injections consisted of $0.3 \%$ hydroxypropyl cellulose in phosphate buffered saline (HPC+PBS) and were administered in a $500 \mu \mathrm{l}$ subcutaneous bolus over a two minute period to ensure full delivery and absorption of the solution. Experimental injections contained the irreversible aromatase inhibitor exemestane (Sigma-Aldrich, St. Louis, MO) suspended in HPC+PBS. Exemestane aggressively inhibits aromatase activity in a wide array of tissues including the brain and adipose tissue [20-21]. The drug was administered subcutaneously at a dosage of $250 \mathrm{mg} \cdot \mathrm{kg}^{-1}$ per $500 \mu \mathrm{l}$ bolus. This dosing schedule and administration technique has previously been shown to yield maximum inhibition of aromatase activity [2224]. Prior to administration, steps were taken to maintain the sterility of the injection medium by using a standard liquid autoclave cycle prior to storage in a sterile lab container. The exemestane was dissolved in methanol and passed through a 0.2 micron cellulose filter into a sterile mortar to remove impurities in the drug. The methanol was then evaporated and the residue exemestane was pulverized and added to an aliquot of sterile HPC+PBS to form a dispensable suspension for injection.

Exemestane has both aromatase-inhibiting and androgenic properties. It was speculated that any observed exemestane effect might be due to the androgenic rather than the aromatase inhibiting effects; therefore, the reversible aromatase inhibitor letrozole (Fisher Scientific, Pittsburgh, PA) was used to validate the results achieved in the exemestane phase of the project. Letrozole was administered via sub-cutaneous injections at a concentration of $0.5 \mu \mathrm{g}$ per $100 \mu \mathrm{l}$ of $0.3 \%$ HPC+PBS for seven days using; the dosing schedule and administration techniques used for letrozole injections followed well established methods [25]. Placebo injections consisted of $0.3 \%$ HPC+PBS.

To vary the levels of circulating steroids, two procedures were employed. First, supplementation or replacement of steroids was achieved via silastic (Dow Corning, Midland, MI) implants. Our silastic implant technique has a long established and validated record of supplementation/replacement and has previously been shown to modulate steroid levels in rodents [26-33]. Thus, testosterone and $17 \beta$-estradiol (Sigma-Aldrich, St. Louis, MO) were packed into $10 \mathrm{~mm}$ lengths of silastic tubing (Dow Corning, Midland, MI) with an internal diameter of $1.02 \mathrm{~mm}$, external diameter of $2.16 \mathrm{~mm}$, and wall thickness of $0.56 \mathrm{~mm}$. The ends of the tubing were capped with clear silicone glue. Placebo implants were left empty. The implants were surgically inserted under isoflurane anesthesia in a small subcutaneous pocket on the lateral aspect of the neck/back between the skin and the muscle fascia. A two day recovery after the silastic implant surgery was allowed prior to reintroduction of running wheels.

The second technique for altering the levels of circulating steroids was the completion of bilateral orchidectomy surgeries to remove the testes, the major sex steroid producing tissue in male mammals. The surgeries were performed under isoflurane anesthesia after preemptive administration of the analgesic carprofen $\left(5 \mathrm{mg} \cdot \mathrm{kg}^{-1}\right)$. A small incision was made in the midline of the scrotum just inferior to the penis. Each testis was exposed through the incision and was removed along with the epididymis. The incision was closed with a sterile wound clip and the animal was allowed to recover under a heating lamp. Placebo animals received a sham procedure; the testis were exposed but were not excised. The surgical procedures were followed by ten days of recovery without access to running wheels.

Experiment One (Figure 1): Twenty mice, stratified by original group housing, were randomly assigned to a placebo $(n=10)$ or experimental $(\mathrm{n}=10)$ group. In both groups, wheel running was monitored under three conditions. First, both groups underwent baseline screening for seven days to assess normal wheel running activity. Next, each mouse received either placebo or exemestane injections; wheel running was monitored for an additional seven days. Lastly, mice were allowed three days of unmonitored wheel running followed by a final seven days to assess wheel running during drug clearance.

To verify the results of experiment one, twenty untreated C57BL/6J mice were used in a confirmatory study with methodological techniques identical to experiment one. In brief, placebo $(n=10)$ or letrozole $(n=10)$ injections were given to reproductively intact mice. Wheel running indices were monitored prior to injections, during injections, and after cessation of injections-each phase lasting seven days. Upon confirmation, further experiments were conducted utilizing exemestane because the androgenic effects of the drug were considered negligible.

Experiment Two (Figure 1): Thirty mice were used in experiment two to evaluate the effects of supplemented sex steroids on wheel running activity during exemestane injections in mice with fully functional reproductive organs. One mouse was euthanized at the onset of the experiment due to an injury sustained during the preliminary group housing phase. The mice were randomly divided into control $(n=9)$, experimental A $(n=10)$, and experimental B $(n=10)$ groups. Wheel running was again assessed at baseline under normal physiological conditions for seven days. During the next seven days of wheel running activity, the mice received exemestane (experimental A and B groups) or placebo (control) injections. In the final seven days of this experiment, the mice received silastic implants containing testosterone (experimental A group) or $17 \beta$-estradiol (experimental B group). The control animals received empty implants. After a brief two day recovery, exemestane and control injections were resumed and wheel running was evaluated for seven additional days.

Experiment Three (Figure 1): The third experimental procedure utilized thirty mice and evaluated the effects of orchidectomy and aromatase inhibition on wheel running activity. Replacement strategies (via silastic implants) were employed to reintroduce the sex steroids 


\section{Experiment 1}

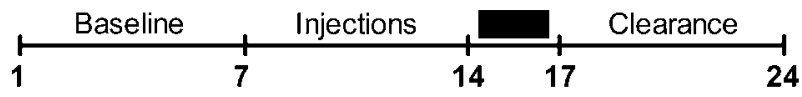
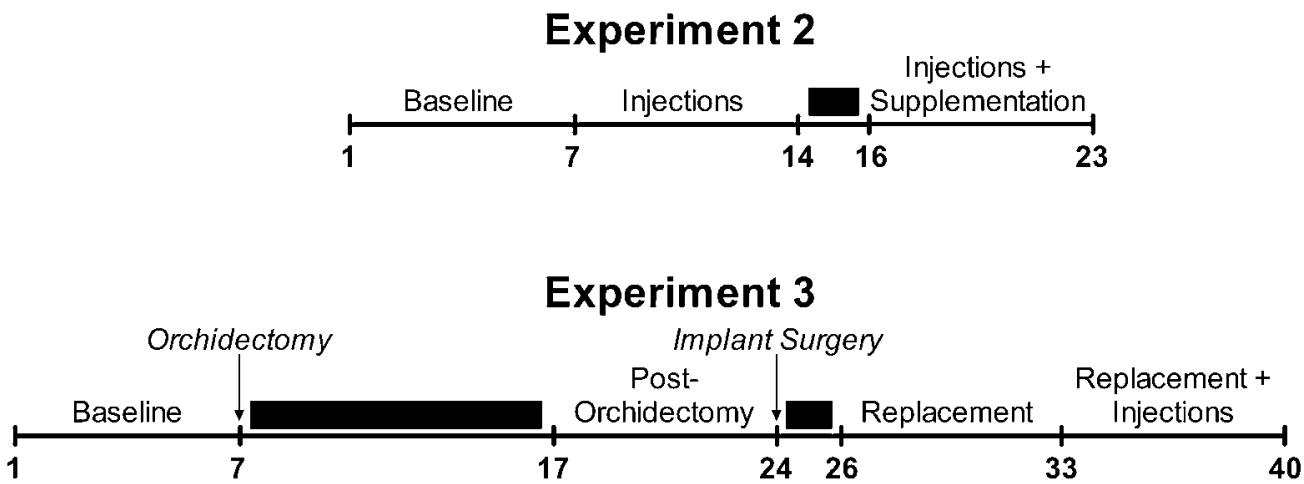

Figure 1: The experimental timelines (days) for assessing physical activity levels in aromatase inhibited and sex steroid modified mice. Black bars represent recovery periods-after surgeries and after cessation of injections-in which running wheels were not in the cages.

after removal of the gonads. The experimental groupings were the same as experiment two. Baseline data was collected at the onset of the experiment over a seven day period. Double and sham orchidectomies were performed and were followed by a ten day recovery period. Wheel running was evaluated at the end of the orchidectomy recovery period for seven days. Silastic implant surgeries were performed followed by two days of recovery. Seven more days of wheel running was assessed following the recovery period. Testosterone, $17 \beta$-estradiol, and blank implants were again utilized during this period. A final seven days of wheel running was assessed while placebo or exemestane injections were administered every 24 hours. The silastic capsules remained in place.

The physical activity data collected during each of the four experiments were analyzed using individual two-way (group by condition) analysis of variance (ANOVA) tests for each wheel running indices (distance, duration, or speed). A Tukey's post-hoc test was used to assess significant main effects or interactions. The alpha level was set a priori at 0.05 .

\section{Results}

Wheel running indices (experiment one) for male C57BL/6J mice at baseline, receiving exemestane or placebo injections, and during a 10-day clearance period are shown in Figure 2a-c. Blocking aromatase did not inhibit activity and did not significantly alter any of the wheel running indices (distance: $p=0.61$, duration: $p=0.38$, or speed: $p=0.69$ ) at the administered dosage $\left(250 \mathrm{mg} \cdot \mathrm{kg}^{-1}\right)$.

The wheel running response under a reversible aromatase inhibitor was similar to the response observed with exemestane inhibition. All wheel running parameters were unaffected by letrozole administration and did not deviate from the levels measured in the control animals (distance: $p=0.24$, duration: $p=0.11$, or speed: $p=0.34$ ). The data for wheel running distance are depicted in Figure 2d; trends for the duration and speed indices were similarly non-significant.
Running distance, duration, and speed for experiment two are shown in Figure 3. Wheel running was assessed at baseline, with exemestane injections, and after implantation of testosterone or $17 \beta$-estradiol containing capsules. The difference across experimental conditions and groups were non-significant (distance: $p=0.66$, duration: $p=0.61$, speed: $p=0.56)$ with neither testosterone nor $17 \beta$-estradiol altering the running response.

Wheel running indices (experiment three) at baseline, after surgical or sham orchidectomies, with placebo, testosterone, or $17 \beta$-estradiol implants, and with injections of placebo vehicle or exemestane are shown in Figure 4. Wheel running was significantly altered by these experimental interventions (distance: $F=4.65, p=0.0001$, duration: $F=4.82, p=0.0001$, speed: $F=6.63, p=0.0001)$ and Tukey's HSD post-hoc tests revealed that several interventions altered the three wheel running activity indices measured (Figure 4). Orchidectomies significantly reduced all three indices of wheel running and testosterone replacement recovered wheel running back to baseline levels; however, $17 \beta$-estradiol failed to engender the same level of recovery. There was no significant alteration to activity with administration of exemestane in orchidectomized mice receiving either steroid.

\section{Discussion}

Our results demonstrate that activity remains unaffected by the administration of aromatase inhibitors at a dosage of $250 \mathrm{mg} \cdot \mathrm{kg}^{-1}$. The results of this study call into question the limited data that has generated the hypothesis of a primary estrogen-derived activity regulating mechanism. These data add additional impetus for further investigation into the effect of sex-steroids on physical activity in both rodent and human populations, with a needed subsequent focus on pathway identification and molecular mechanisms. Additional studies that focus on the effects the aromatase complex has on activity level regulation is warranted. The current project represents a seminal modus operandi in this new avenue of hormonal and steroidal research. 
A physiologically normal C57BL/6J mouse runs vigorously when exposed to a running wheel (see Figures 2-4; baseline running data). Alterations to circulating sex steroid concentrations interrupt this normal running pattern [34-37], an effect postulated to occur through the modulation of estrogen levels via the aromatase complex; an assertion primarily based on limited previous research [14]. However, inhibition of the aromatase complex did not significantly alter wheel running activity indicating that a functional aromatase complex may not be required for activity levels to be modulated or maintained at normal levels in the reproductively intact rodent. While contradictory to previous speculations, other than Roy and Wade's [14] data, little direct evidence exists that indicates activity regulation-via the sex steroids-requires the presence of estrogenic compounds.

Roy and Wade [14] assessed the ability of testosterone propionate (an aromatizable androgen) and dihydrotestosterone propionate (a non-aromatizable androgen) to affect activity levels in castrated male rats. Administration of the aromatizable androgen increased activity to the levels observed in estrogen treated animals, but the nonaromatizable androgen had little effect on activity level [14]. Roy and Wade [14] noted only a partial $(\sim 45 \%)$ recovery of wheel running with testosterone administration ( $\sim 4000$ revolutions) compared to estradiol benzoate administration ( 9000 revolutions). With testosterone administration, we observed that wheel running not only returned to the levels observed at baseline, but also was notably elevated above the levels induced by $17 \beta$-estradiol administration (Figure 4). The difference in testosterone-driven activity between our and Roy and Wade's study may be accounted for by the modes of steroid delivery used. The steroidal compounds were delivered via silastic implants in the current project, but Roy and Wade [14] delivered the steroids via daily injections in sesame oil. The injection methods employed by Roy and Wade [14] required daily contact with the animals, which has been shown to induce higher levels of stress with resultant decreases in wheel running activity [38]. However, the effects of human interaction on wheel running behavior observed by Richter [38] were not as dramatic as the differences noted between our results and Roy and Wade's [14]. Therefore, though this certainly may explain some of the differences between our study and Roy and Wade's [14], it is likely that other mechanisms also exist that account for this discrepancy.

Watai et al. [15] evaluated activity in an aromatase (Cyp19) knockout mouse model and observed very low activity levels in these mice. Replacement of $17 \beta$-estradiol elevated activity in male knockout mice suggesting a requirement for estrogens to be present in order for activity levels to match those observed in normal animals [15]. The use of gene knockout models are not without adversity as developmental differences in mice can result in an obscured representation of reality [17] as well as potential elimination of neighboring regulatory genomic regions in the knockouts [39]. Thus, the results of Watai et al. [15] may be due to such unintended effects and therefore the result of abnormal physiological phenomenon rather than relevant deviations in the mechanisms affecting activity levels.

Conversely, Hill et al. [16] evaluated wheel running activity in estrogen deficient male mice, similar to the mice utilized by Watai et al. [15] and observed compulsory wheel running activity that exceeded the levels observed in wild type controls suggesting that estrogen was inhibiting activity in this model. Interestingly, this effect was not observed in female Cyp19 (aromatase) knockout animals. In addition, compulsory wheel running was ameliorated after the administration of $17 \beta$-estradiol in the male, but not female knockout mice [16]. The non-essential need for a functional aromatase complex to maintain normal activity levels observed in the present study and by Hill et al. [16] is contrary to the observations of Roy and Wade [14] and Watai et al. [15]. The technical difference noted in these studies may account a

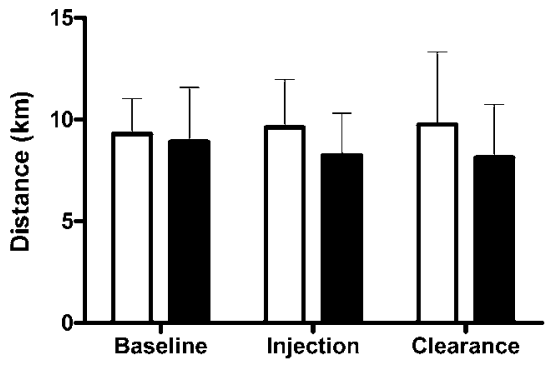

C

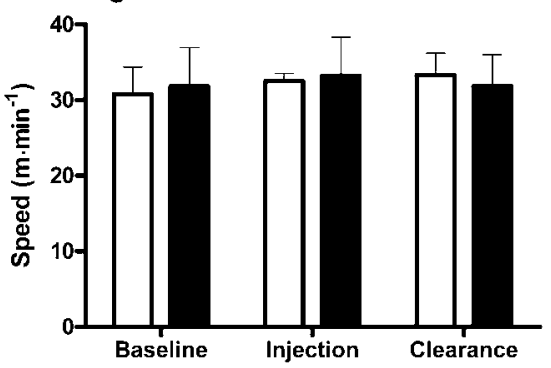

b

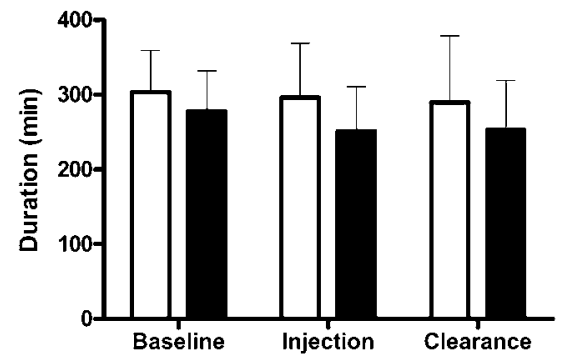

d

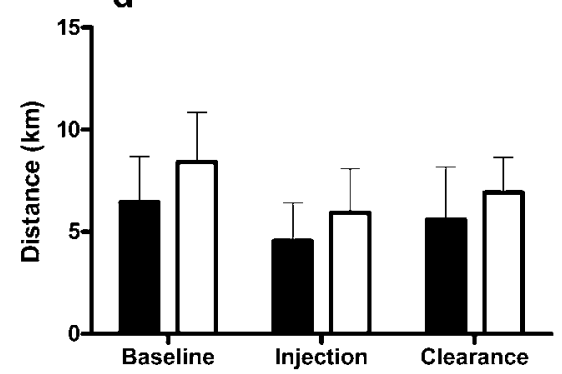

Figure 2: Wheel running indices for male C57BL/6J mice at baseline, during injections, and during post-injection clearance. White bars denote control mice ( $\mathrm{n}=10$ ) that received vehicle injections and black bars denote experimentally treated mice $(n=10)$ that received exemestane (panels a-c; distance, duration, speed) or letrozole (panel d; distance) injections. 

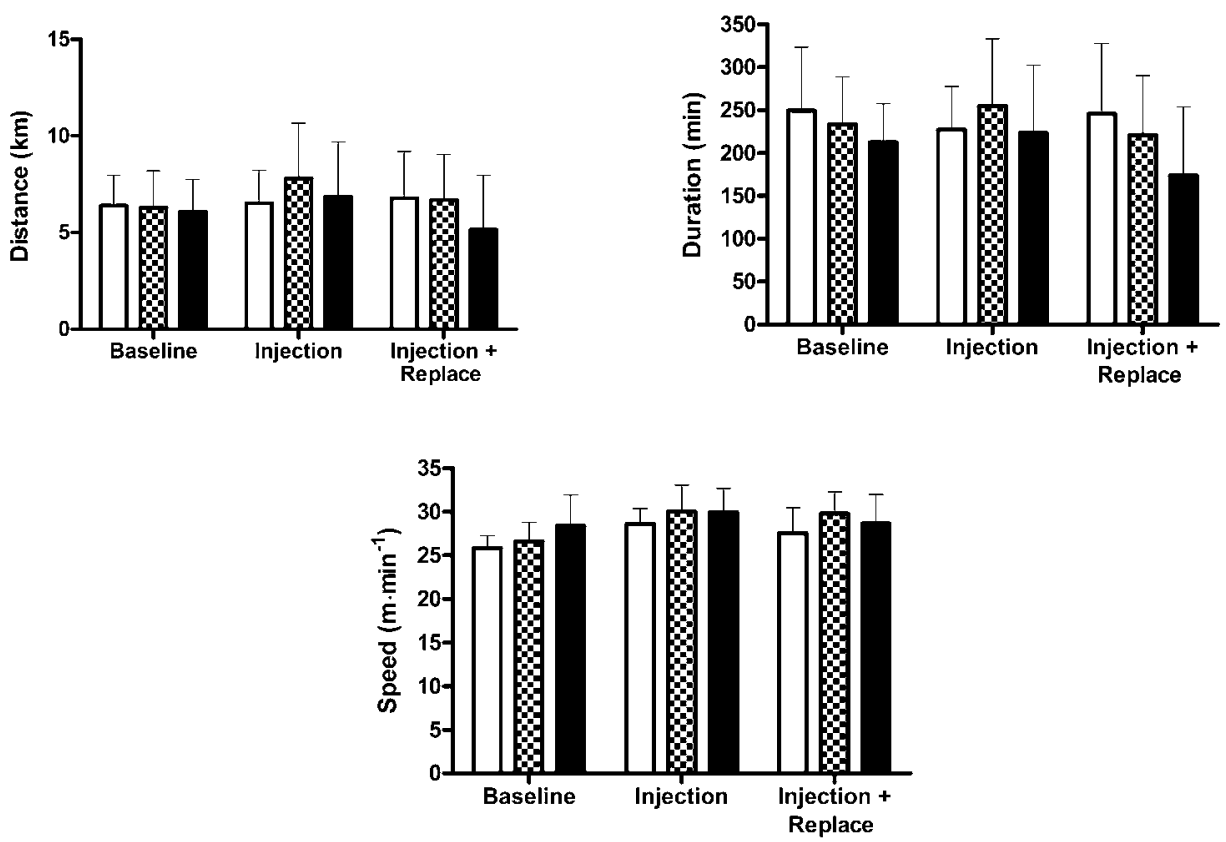

Figure 3: Wheel running indices (distance, duration, and speed) for male C57BL/6J mice at baseline, during injections, and during injections supplemented with eithe testosterone or $17 \beta$-estradiol. White bars denote control mice $(n=9)$ that received vehicle injections and empty silastic implants. Checkered bars denote experimentally treated mice $(n=10)$ that received exemestane injections and silastic implants containing testosterone. Black bars denote experimentally treated mice $(n=10)$ that received exemestane injections and silastic implants containing $17 \beta$-estradiol.
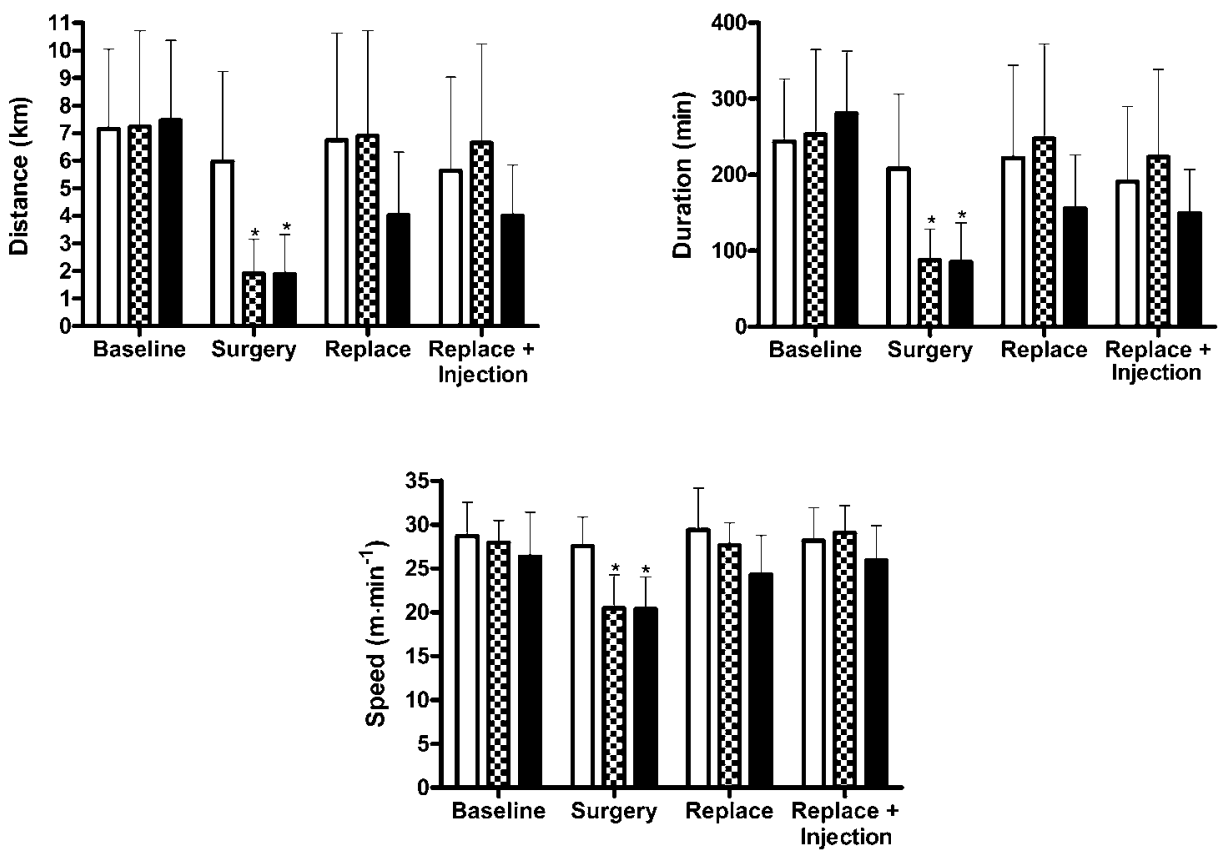

Figure 4: Wheel running indices (distance, duration, and speed) for male C57BL/6J mice at baseline, during injections, during steroid replacement, and during steroid replacement with injections. White bars denote control mice $(n=10)$ that received vehicle injections and empty silastic implants. Checkered bars denote experimentally treated mice $(n=10)$ that received silastic implants containing testosterone and exemestane injections. Black bars denote experimentally treated mice $(n=10)$ that received silastic implants containing $17 \beta$-estradiol and exemestane injections. ${ }^{*}=$ significantly different from controls and baseline values.

for some of the observational disparities; however, it is obvious that testosterone may have a stronger effect on physical activity than previously understood thus justifying further study detailing the underlying estrogenic and androgenic mechanisms.
The potential identity of the androgenic steroid mechanisms modulating physical activity remains unclear. Two primary lines of evidence from the current project support the presence of an androgenic activity regulator. First, blockade of the aromatase 
complex via either reversible or irreversible aromatase inhibiters did not significantly reduce wheel running in reproductively intact or sex steroid treated orchidectomized male mice. Second, testosterone replacement in orchidectomized male mice increased wheel running activity back to baseline levels, while $17 \beta$-estradiol increased wheel running to only $50 \%$ of baseline levels. Our data represent the second study to suggest the existence of a direct androgenic mechanism in non-genetically modified mice. Flynn et al. [40] exposed mice to the anti-androgenic fungicide vinclozolin at gestational age seven in dam's milk and continued exposure via food after weaning. With exposure to vinclozolin and the resultant androgenic-inhibition, both males and females exhibited decreased wheel running levels; however, only the females reached a statistically significant decrease in wheel running activity at the highest dose of the chemical. The authors [40] concluded that the depressive effects of vinclozolin on activity levels were caused by an inhibitory interaction between the fungicide and the androgen receptor. Thus, the data of Flynn et al. [40] partially supports our hypothesis regarding the existence of an androgenic physical-activity regulating mechanism.

While several authors [41-45] have suggested that the high malleability of the activity response in animals treated with estrogens is a centrally-located (i.e. brain) function, the permeability of the rodent brain to androgens is also high [46] suggesting a potential pathway through which testosterone affects physical activity. To date, only one paper [47] has evaluated brain morphology in aromatase compromised mice and noted lower levels of dopaminergic neurons in the medial preoptic area and arcuate nucleus of male knockout mice. This response would tentatively explain the noted increased activity levels of the aromatase knockout mice based on recent work from Knab et al. [7] that suggested an increased activity level was due to down-regulated dopamine 1 receptor levels. It is hypothesized by Knab et al. [7] that dopamine receptor reward signaling is decreased due to the lower number of receptor containing neurons and to compensate, mice run more, thus initiating a reward signal on a more frequent basis through the reduced number of receptor containing neurons. Therefore, we speculate that testosterone influences activity levels in male mice through interactions with the androgen receptor leading to alteration of central dopamine functioning.

The injection and sampling techniques employed in this project required close contact with the mice several times throughout the study. Interactions between animal handlers and small rodents have been shown to induce a stress response in small rodents [38] which could artificially alter sex steroid levels and wheel running patterns. Steps were taken to minimize stress in this study for humane purposes and to limit the potential to induce aberrant sex steroid concentrations and unnatural running patterns. During all procedures, animals were handled using controlled and secure techniques, monitored for signs of elevated stress (vocalizations, biting, increased mobility, etc.), and directly exposed to technicians for a minimal amount of time. Most contact from initial immobilization to release back into the home cage was less than three minutes. The effectiveness of drug administration to reduce aromatase activity in the study's mouse population was assured through use of routine and previously described techniques. As stated before, the dosage and technique used in this project are a common methodology to reduce aromatase activity in rodents [22-24]. The only major concern was a potential bias induced by multiple handlers during injection events. To circumvent these issues, an individual technician prepared and performed delivery of both pharmaceutical agents using the described simple, effective methods. This well-trained technician is a highly proficient animal handler.
Exemestane is an irreversible aromatase inhibiting drug. In addition to its inhibitory effects, exemestane has been shown to possess androgenic characteristics in clinical situations including an affinity to bind the androgen receptor [48]. The dosage used in this project was previously shown to have physiological effects on bone characteristics, tumor morphology, and estrogen production. These effects could have been due to the androgenic rather than the aromatase inhibitory nature of exemestane. In order to parse the androgenicity and aromatase inhibitory effects of the drug, the results from the first experiment were repeated using letrozole, a reversible aromatase inhibitor that does not have androgenic effects. Using letrozole, similar results were observed as with exemestane indicating that the aromatase inhibiting effects of the drugs did not alter wheel running behavior and that physical activity regulation via estrogenic sources was not an absolute requirement in our model.

The present study evaluated the effects of two aromatase inhibitors on wheel running activity in male C57BL/6J mice. Neither aromatase inhibitor altered wheel running activity in intact, supplemented, or orchidectomized animals. These data, in conjunction with wheel running measures in aromatase knockout mice [16] and vinclozolin treated mice [40], suggests that aromatization of testosterone is not an absolute requirement for activity regulation as has been earlier postulated [14] and that a direct androgenic mechanism regulates activity levels in mice. This proposed androgenic mechanism is likely an additional effect supplementing and/or offsetting the effects of the estrogenic compounds. The complexity of such regulatory mechanisms and the low number of available research studies provide ample basis for reinvigoration of this research area. In particular, studies that partition the androgenic and aromatase inhibitory effects of the irreversible aromatase inhibitors will provide valuable insight into this mechanism. Future research should also utilize pharmacological and chemical methods to manipulate the function of the aromatase complex and androgen receptors of intact and gonadectomized mice while monitoring wheel running. Physical inactivity has reached epidemic proportions in the developed world leading to increasing rates of obesity and hypokinetic diseases; thus identifying and understanding the biological mechanisms that regulate activity levels could profoundly influence human health worldwide.

\section{Acknowledgments}

The project described was supported by grants from the National Institutes of Health (NIAMS AR050085), the American College of Sports Medicine Foundation (Doctoral Research Grant Award), and Sigma Xi (Grants-in-Aid of Research). The authors would like to thank the UNC Charlotte Vivarium staff for assistance with animal husbandry needs and Ms. Alicia T. Hamilton for assistance with laboratory techniques.

\section{References}

1. Mokdad AH, Marks JS, Stroup DF, Gerberding JL (2004) Actual causes of death in the United States, 2000. JAMA 291: 1238-1245.

2. Joosen AM, Gielen M, Vlietinck R, Westerterp KR (2005) Genetic analysis of physical activity in twins. Am J Clin Nutr 82: 1253-1259.

3. Stubbe JH, Boomsma DI, Vink JM, Cornes BK, Martin NG, et al. (2006) Genetic influences on exercise participation in 37,051 twin pairs from seven countries. PLOS ONE 1: 22

4. Lightfoot JT, Turner MJ, Daves M, Vordermark A, Kleeberger SR (2004) Genetic influence on daily wheel running activity level. Physiol Genomics 19 : 270-276.

5. Leamy LJ, Pomp D, Lightfoot JT (2008) An epistatic genetic basis for physica activity traits in mice. J Hered 99: 639-646

6. Lightfoot JT, Turner MJ, Pomp D, Kleeberger SR, Leamy LJ (2008) Quantitative trait loci for physical activity traits in mice. Physiol Genomics 32: 401-408. 
Citation: Bowen RS, Ferguson DP, Lightfoot JT (2011) Effects of Aromatase Inhibition on the Physical Activity Levels of Male Mice. J Steroids Hormon Sci S1:001. doi:10.4172/2157-7536.S1-001

7. Knab AM, Bowen RS, Hamilton AT, Gulledge AA, Lightfoot JT (2009) Altered dopaminergic profiles: implications for the regulation of voluntary physical activity. Behav Brain Res 204: 147-152.

8. Lightfoot JT, Leamy L, Pomp D, Turner MJ, Fodor AA, et al. (2010) Strain screen and haplotype association mapping of wheel running in inbred mouse strains. J Appl Physiol 109: 623-634

9. Ogawa S, Chan J, Gustafsson JA, Korach KS, Pfaff DW (2003) Estrogen increases locomotor activity in mice through estrogen receptor alpha: specificity for the type of activity. Endocrinology 144: 230-239.

10. Morgan MA, Schulkin J, Pfaff DW (2004) Estrogens and non-reproductive behaviors related to activity and fear. Neurosci Biobehav Rev 28: 55-63.

11. Gorzek JF, Hendrickson KC, Forstner JP, Rixen JL, Moran AL, et al. (2007) Estradiol and tamoxifen reverse ovariectomy-induced physical inactivity in mice. Med Sci Sports Exerc 39: 248-256.

12. Hydock DS, Lien CY, Schneider CM, Hayward R (2007) Effects of voluntary wheel running on cardiac function and myosin heavy chain in chemically gonadectomized rats. Am J Physiol Heart Circ Physiol 293: 3254-3264.

13. Lightfoot JT (2008) Sex hormones' regulation of rodent physical activity: a review. Int J Biol Sci 4: 126-132.

14. Roy EJ, Wade GN (1975) Role of estrogens in androgen-induced spontaneous activity in male rats. J Comp Physiol Psychol 89: 573-579.

15. Watai K, Tsuda M, Nakata M, Toda K, Ogawa S (2007) Analyses of running wheel activity (RWA) in aromatase-knockout (ArKO) mice. Neurosci Res 58: 108

16. Hill RA, Mclnnes KJ, Gong EC, Jones ME, Simpson ER, et al. (2007) Estrogen deficient male mice develop compulsive behavior. Biol Psychiatry 61: 359-366.

17. Chapman PF (2002) Giving drugs to knockout mice: can they do that? Trends Neurosci 25: 277-279.

18. Swallow JG, Garland T, Jr., Carter PA, Zhan WZ, Sieck GC (1998) Effects of voluntary activity and genetic selection on aerobic capacity in house mice (Mus domesticus). J Appl Physiol 84: 69-76.

19. Knab AM, Bowen RS, Moore-Harrison T, Hamilton AT, Turner MJ, et al. (2009) Repeatability of exercise behaviors in mice. Physiol Behav 98: 433-440.

20. Santen RJ, Brodie H, Simpson ER, Siiteri PK, Brodie A (2009) History of Aromatase: Saga of an Important Biological Mediator and Therapeutic Target. Endocr Rev 30: 343-375

21. Attar E, Bulun SE (2006) Aromatase inhibitors: the next generation of therapeutics for endometriosis? Fertil Steril 85: 1307-1318.

22. Goss PE, Qi S, Cheung AM, Hu H, Mendes M, et al. (2004) Effects of the steroidal aromatase inhibitor exemestane and the nonsteroidal aromatase inhibitor letrozole on bone and lipid metabolism in ovariectomized rats. Clin Cancer Res 10: 5717-5723.

23. Jelovac D, Macedo L, Handratta V, Long BJ, Goloubeva OG, et al. (2004) Effects of exemestane and tamoxifen in a postmenopausal breast cance model. Clin Cancer Res 10: 7375-7381.

24. di Salle E, Briatico G, Giudici D, Ornati G, Zaccheo T (1989) Aromatase inhibition and experimental antitumor activity of FCE 24304, MDL 18962 and SH 489. J Steroid Biochem 34: 431-434

25. Luthra R, Kirma N, Jones J, Tekmal RR (2003) Use of letrozole as a chemopreventive agent in aromatase overexpressing transgenic mice. J Steroid Biochem Mol Biol 86: 461-467.

26. Bowman RE, Ferguson D, Luine VN (2002) Effects of chronic restraint stress and estradiol on open field activity, spatial memory, and monoaminergic neurotransmitters in ovariectomized rats. Neuroscience 113: 401-410.

27. Broida J, Svare B (1983) Genotype modulates testosterone-dependent activity and reactivity in male mice. Horm Behav 17: 76-85

28. Cohen PE, Milligan SR (1993) Silastic implants for delivery of oestradiol to mice. J Reprod Fertil 99: 219-223.

29. Daan S, Damassa D, Pittendrigh CS, Smith ER (1975) An effect of castration and testosterone replacement on a circadian pacemaker in mice (Mus musculus). Proc Natl Acad Sci U S A 72: 3744-3747.

30. Ellis GB, Turek FW (1983) Testosterone and photoperiod interact to regulate locomotor activity in male hamsters. Horm Behav 17: 66-75.

This article was originally published in a special issue, Hormonomics handled by Editor(s). Dr. Ram Ramabhadran, Research Triangle Park, USA
31. Garey J, Morgan MA, Frohlich J, McEwen BS, Pfaff DW (2001) Effects of the phytoestrogen coumestrol on locomotor and fear-related behaviors in female mice. Horm Behav 40: 65-76.

32. Morin LP, Cummings LA (1982) Splitting of wheelrunning rhythms by castrated or steroid treated male and female hamsters. Physiol Behav 29: 665-675.

33. Pieper DR, Lobocki CA, Lichten EM, Malaczynski J (1999) Dehydroepiandrosterone and exercise in golden hamsters. Physiol Behav 67 607-610.

34. Hoskins RG (1925) Studies on vigor. II. The effect of castration on voluntary activity. Am J Physiol 72: 324-330.

35. Hoskins RG (1925) Studies on vigor. VI. The effects of starvation on the spontaneous activity of castrated rats. Endocrinology 9: 403-406.

36. Wang GH, Richter CP, Guttmacher AF (1925) Activity studies on male castrated rats with ovarian transplants and correlation of the activity with the histology of the grafts. Am J Physiol 73: 581-599.

37. Richter CP (1933) The effect of early gonadectomy on the gross body activity of rats. Endocrinology 17: 445-450.

38. Richter CP (1976) Artifactual seven-day cycles in spontaneous activity in wild rodents and squirrel monkeys. J Comp Physiol Psychol 90: 572-582.

39. Osokine I, Hsu R, Loeb GB, McManus MT (2008) Unintentional miRNA ablation is a risk factor in gene knockout studies: a short report. PLoS Genet 4: 34

40. Flynn KM, Delclos KB, Newbold RR, Ferguson SA (2001) Behavioral responses of rats exposed to long-term dietary vinclozolin. J Agric Food Chem 49: 16581665.

41. Kennedy GC (1964) Hypothalamic control of the endocrine and behavioura changes associated with oestrus in the rat. J Physiol 172: 383-392.

42. Colvin GB, Sawyer CH (1969) Induction of running activity by intracerebra implants of estrogen in overiectomized rats. Neuroendocrinology 4: 309-320.

43. Hitt JC, Gerall AA (1969) Effect of brain stimulation on estrous activity cycles Psychol Rep 24: 59-68.

44. Wade GN, Zucker I (1970) Modulation of food intake and locomotor activity in female rats by diencephalic hormone implants. J Comp Physiol Psychol 72 328-336.

45. Gentry RT, Wade GN, Roy EJ (1976) Individual differences in estradiol-induced behaviors and in neural 3H-estradiol uptake in rats. Physiol Behav 17: 195-200.

46. Pardridge WM, Mietus LJ (1979) Transport of steroid hormones through the rat blood-brain barrier. Primary role of albumin-bound hormone. J Clin Invest 64 145-154.

47. Hill RA, Pompolo S, Jones ME, Simpson ER, Boon WC (2004) Estrogen deficiency leads to apoptosis in dopaminergic neurons in the medial preoptic area and arcuate nucleus of male mice. Mol Cell Neurosci 27: 466-476.

48. Johannessen DC, Engan T, Di Salle E, Zurlo MG, Paolini J, et al. (1997) Endocrine and clinical effects of exemestane (PNU 155971), a novel steroidal aromatase inhibitor, in postmenopausal breast cancer patients: a phase study. Clin Cancer Res 3: 1101-1108. 